\title{
Electrochemical, Spectroscopic, and Thermal Studies on Interactions of Linear Poly(acrylic acid) with Uranyl Ions in Aqueous Solutions
}

\author{
ARTEM V. DUBOLAZOV, ${ }^{1}$ OLGUN GÜVEN, ${ }^{2}$ NURSEL PEKEL, ${ }^{2}$ GALIYA S. AZHGOZHINOVA, ${ }^{1}$ \\ GRIGORIY A. MUN, ${ }^{1}$ ZAURESH S. NURKEEVA ${ }^{1}$ \\ ${ }^{1}$ Department of Chemical Physics and Macromolecular Chemistry, Kazakh National University, Karasai Batyra 95, \\ 480012 Almaty, Kazakhstan \\ ${ }^{2}$ Department of Chemistry, Hacettepe University, Beytepe 06532, Ankara, Turkey
}

Received 29 August 2003; revised 15 October 2003; accepted 8 December 2003

\begin{abstract}
The formation of complexes between linear poly(acrylic acid) (PAA) and uranyl ions in aqueous solutions was studied with conductometry, potentiometry, thermal analysis, Fourier transform infrared, and luminescence spectroscopy methods. The stoichiometry of the PAA/ $\mathrm{UO}_{2}^{2+}$ complex on repeating units of a PAA basis was determined to be 2:1. IR spectroscopy studies made on solid complexes showed that the carbonyl stretching absorption band of PAA was shifted to a higher wave number, and a new band at 1749 $\mathrm{cm}^{-1}$ in the polycomplex spectrum was observed, confirming the existence of specific interactions between the carboxylate groups of PAA and metal ions. Luminescence spectroscopy studies showed an increase in the intensity of the uranyl-ion emission spectra and new band formation at $483 \mathrm{~nm}$, further confirming the interaction of $\mathrm{UO}_{2}^{2+}$ ions with PAA in aqueous solutions. The thermal behavior of $\mathrm{PAA} / \mathrm{UO}_{2}^{2+}$ complexes further proved strong interactions in the complex structure. The thermal degradation of the polycomplexes included the main stages of destruction of both PAA and uranyl nitrate. () 2004 Wiley Periodicals, Inc. J Polym Sci Part B: Polym Phys 42: 1610-1618, 2004
\end{abstract}

Keywords: uranyl ions; poly(acrylic acid); metal-polymer complexes; polyelectrolytes; luminescence

\section{INTRODUCTION}

One of the most interesting features of polyelectrolytes is their ability to form polycomplexes with oppositely charged small and big molecules because of Coulombic interactions. The investigation of the complex formation of polyelectrolytes with metal ions is of great importance because of the possibility of applying this process to pollu-

\footnotetext{
Correspondence to: O. Güven (E-mail: guven@ hacettepe.edu.tr)

Journal of Polymer Science: Part B: Polymer Physics, Vol. 42, 1610-1618 (2004) () 2004 Wiley Periodicals, Inc.
}

tion control and wastewater treatment, enrichment technologies, catalysis, and so forth. ${ }^{1-5}$

Poly(acrylic acid) (PAA) is a polyelectrolyte containing hydrophilic carboxyl groups in every repeating unit. The presence of carboxylate ions along the polymeric chain ensures the possibility of forming polycomplexes with positively charged moieties and metal ions, the latter being coordinated to one or more $\mathrm{COO}^{-}$groups. ${ }^{6,7}$ The stability of these polycomplexes depends on various factors, such as the polycomplex preparation conditions, the structure of the polymer and/or lowmolecular-weight species, the concentrations of the components, the temperature, the nature of the solvent, and the $\mathrm{pH}$. Mathew et al. ${ }^{8}$ studied 
the complexation of PAA with different transition-metal ions by IR and ultraviolet-visible spectroscopy and by the thermal analysis of solid complexes. They found that increasing the $\mathrm{pH}$ of aqueous solutions improved the metal-ion uptake with subsequent complexation. The stability of polycomplexes arises from the formation of stable coordination geometries within the polymer backbone.

Morcellet et al. ${ }^{9}$ studied the ligand concentration effect on the formation of metal complexes between PAA and divalent, trivalent, and tetravalent metal ions. The complex formation constants decreased with increasing polymer concentration.

Akman et al. ${ }^{10}$ showed the possibility of using water-soluble PAA for the preconcentration and separation of some metal ions $\left(\mathrm{Zn}^{2+}, \mathrm{Cu}^{2+}\right.$, and $\left.\mathrm{Cd}^{2+}\right)$. They found that these ions were quantitatively $( \pm 0.5 \%)$ collected by the polymer over a wide $\mathrm{pH}$ range of 3-9.

Pochard et al. ${ }^{11}$ investigated the specificity of the exchange between divalent $\left(\mathrm{Ca}^{2+}\right.$ and $\left.\mathrm{Ba}^{2+}\right)$ and monovalent $\left(\mathrm{Li}^{+}, \mathrm{Na}^{+}\right.$, and $\left.\mathrm{K}^{+}\right)$ions onto PAA chains with conductometry and microcalorimetry techniques. They found that the complexation with $\mathrm{Ca}^{2+}$ and $\mathrm{Ba}^{2+}$ implied a monotonous release of condensed monovalent ions accompanied by a reduction in the number of ionized carboxyl groups of PAA.

Some investigations have been devoted to the doping of PAA by metal clusters. Cardenas et al. ${ }^{12}$ incorporated different metal clusters into PAA within the range of $0.22-13.3 \%(\mathrm{w} / \mathrm{w})$. The thermal degradation of the clusters was not ordinary but depended on the nature of the metal ion.

Rosendo et al. ${ }^{13}$ prepared PAA doped with $\mathrm{Eu}^{3+}$ and $\mathrm{Tb}^{3+}$ and showed that the dopant ions could be incorporated into the polymer through the formation of strong lanthanide-oxygen chemical bonds.

Luminescence methods have been increasingly used to examine different types of interactions because of their inherent sensitivity. The luminescence properties of lanthanide $\left(\mathrm{Eu}^{3+}, \mathrm{Tb}^{3+}\right.$, etc.) and actinide ions such as $\mathrm{UO}_{2}^{2+}$ in aqueous solutions are well known. Their applications help to establish, for example, transitions between different structures and phases and distinctions between intramolecular and intermolecular association. ${ }^{13-15}$ Nagata and Okamoto ${ }^{16}$ investigated metal-ion binding by poly(sodium acrylate) (PSA) with rare-earth $\mathrm{Tb}^{3+}$ metal-ion fluorescence probes. They found that the presence of polyelec- trolytes enhanced the fluorescence intensity of the metal ions in aqueous solutions considerably; this was due to the unique asymmetric PSA environment surrounding $\mathrm{Tb}^{3+}$.

Earlier, Nishide et al. ${ }^{17}$ and Leroy et al. ${ }^{18}$ investigated the complexation of $\mathrm{UO}_{2}^{2+}$ with linear PAA in aqueous solutions by potentiometry and pulse polarography techniques, respectively. They estimated the stoichiometry for the complexation of the $\mathrm{UO}_{2}^{2+}$ by PAA to be 2 and the dissociation constants of the polycomplex to be log $K=9.3^{17}$ and 9.5. ${ }^{18}$ It should be noted that the complexing ability of uranyl ions with PAA ligands is higher than for $\mathrm{PAA} / \mathrm{Cu}^{2+}(\log K=6.6)$, $\mathrm{PAA} / \mathrm{Ni}^{2+}(\log K=5.5), \mathrm{PAA} / \mathrm{Cd}^{2+}(\log K=6.1)$, and $\mathrm{PAA} / \mathrm{Pb}^{2+}(\log K=7.1) ;{ }^{19,20}$ this means higher stability of the PAA/ $\mathrm{UO}_{2}^{2+}$ complex.

This work approaches, from another point of view, the complexation ability of PAA with $\mathrm{UO}_{2}^{2+}$ in aqueous solutions ${ }^{17,18}$ and tries to elaborate the mechanism of complex formation between PAA and uranyl ions in aqueous solutions by luminescence spectroscopy and potentiometry and conductometry techniques with a molar ratio method..$^{21}$ The PAA/ $/ \mathrm{UO}_{2}^{2+}$ complex in the solid form was investigated with Fourier transform infrared (FTIR) spectroscopy and thermogravimetric analysis (TGA) methods.

\section{EXPERIMENTAL}

\section{Materials}

PAA (BDH Co., England), with a weight-average molecular weight of $2.3 \times 10^{5}$, and hexahydrate of uranyl nitrate $\left[\mathrm{UO}_{2}\left(\mathrm{NO}_{3}\right)_{2} \cdot 6 \mathrm{H}_{2} \mathrm{O}\right.$; Merck, Darmstadt, Germany] were used without further purification. The PAA/ $/ \mathrm{UO}_{2}^{2+}$ aqueous solutions were prepared through the addition of PAA of different concentrations ( $\mathrm{mol} \mathrm{L}^{-1}$ on a repeating unit basis) to $\mathrm{UO}_{2}^{2+}$ aqueous solutions $\left(\left[\mathrm{UO}_{2}^{2+}\right]=0.001 \mathrm{~mol}\right.$ $\mathrm{L}^{-1}$ ). All experiments were carried out at the ambient temperature and within $10 \mathrm{~min}$ after the mixing of the components to avoid precipitation of the polycomplex.

For the preparation of the solid $\mathrm{PAA} / \mathrm{UO}_{2}^{2+}$ complex, PAA and $\mathrm{UO}_{2}\left(\mathrm{NO}_{3}\right)_{2} \cdot 6 \mathrm{H}_{2} \mathrm{O}$ were separately dissolved in water (at concentrations of 0.2 $\mathrm{mol} \mathrm{L}{ }^{-1}$ on a repeating unit basis and $0.1 \mathrm{~mol} \mathrm{~L}^{-1}$, respectively) and mixed in a volume ratio of 1:1. A yellowish, solid precipitate formed. The precipitated polycomplex was centrifuged, washed with distilled water several times, and dried in vacuo 


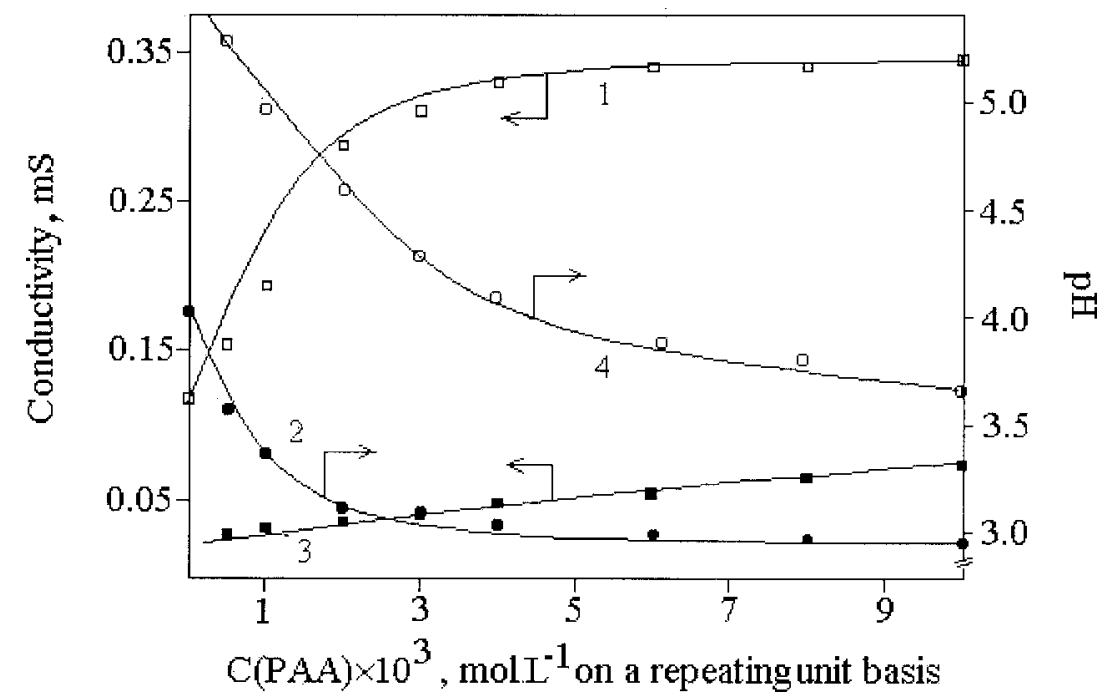

Figure 1. Effect of the PAA concentration on $(1,3)$ the conductivity and $(2,4) \mathrm{pH}$ of aqueous solutions in $(1,2)$ the presence and $(3,4)$ the absence of $\mathrm{UO}_{2}^{2+}\left(\left[\mathrm{UO}_{2}^{2+}\right]=0.001\right.$ $\mathrm{mol} \mathrm{L}-1)$.

to a constant weight. The thermal scan process started after the preheating of the samples until $120{ }^{\circ} \mathrm{C}$ at a scanning rate of $2 \% \mathrm{~min}$ for the removal of residual or superficially bound water. A $13 \%$ weight loss was observed upon the preheating of $\mathrm{UO}_{2}\left(\mathrm{NO}_{3}\right)_{2} \cdot 6 \mathrm{H}_{2} \mathrm{O}$ to $120{ }^{\circ} \mathrm{C}$ and could be attributed to the loss of three water molecules. The final form of preheated uranyl nitrate was, therefore, considered $\mathrm{UO}_{2}\left(\mathrm{NO}_{3}\right)_{2} \cdot 3 \mathrm{H}_{2} \mathrm{O}$.

\section{Methods}

The conductivities of PAA aqueous solutions of different concentrations in the presence and absence of $\mathrm{UO}_{2}^{2+}$ ions were measured with a WPA CM35 conductometer (Linton, Cambridge, United Kingdom). The $\mathrm{pH}$ values of aqueous solutions were determined with a digital pH 211 microprocessor $\mathrm{pH}$ meter (Hanna Instruments, Germany).

The emission spectra of $\mathrm{UO}_{2}^{2+}$ ions before and after complexation with PAA in aqueous solutions were recorded on a PerkinElmer LS 55 luminescence spectrometer (PerkinElmer Instruments, United Kingdom) under excitation at $310 \mathrm{~nm}$. All complex formation experiments were performed between $\mathrm{pH} 2.95$ and $\mathrm{pH} 4.02$ to avoid the hydrolysis of $\mathrm{UO}_{2}{ }^{2+21}$ at $25 \pm 1{ }^{\circ} \mathrm{C}$.

FTIR spectra of solid samples were recorded on a Nicolet 520 FTIR spectrometer (Nicolet Instruments, Madison, WI) in the form of $\mathrm{KBr}$ discs.

The thermal behaviors of PAA, uranyl nitrate trihydrate, and the polycomplex in the solid state were investigated with a 951 thermogravimetric analyzer and a 910 differential scanning calorimeter ( $\mathrm{Du}$ Pont Instruments, United States) at a scanning rate of $10 \%$ min in a dry nitrogen atmosphere. The glass-transition temperature $\left(T_{\mathrm{o}}\right)$ of PAA was determined as the middle value of the reverse S-shape on the differential scanning calorimetry (DSC) curve.

\section{RESULTS AND DISCUSSION}

The complexation of PAA with uranyl ions was studied by potentiometry and conductometry techniques with a molar ratio method. ${ }^{22}$ Figure 1 shows the variation of the $\mathrm{pH}$ and electrical conductivity of $\mathrm{PAA} / \mathrm{UO}_{2}^{2+}$ aqueous solutions as a function of $n$, where $n$ is the molar ratio of PAA repeating units to uranyl ions. An increase in the PAA content leads to a gradual decrease in the $\mathrm{pH}$ values and an increase in the solution conductivity. In both cases, the saturation appears around a 2:1 molar ratio of PAA on a repeating unit basis to $\mathrm{UO}_{2}^{2+}$. The further increase in the PAA concentration in the mixture practically does not affect the $\mathrm{pH}$ and conductivity. The changes in the $\mathrm{pH}$ and conductivity upon the mixing of the two solutions indicate the release of hydrogen ions into solution, which results from the binding of uranyl ions by carboxylate groups of PAA. $n=2$, corresponding to the complexation of 2 repeating units of PAA with 1 uranyl ion via Coulombic forces, 


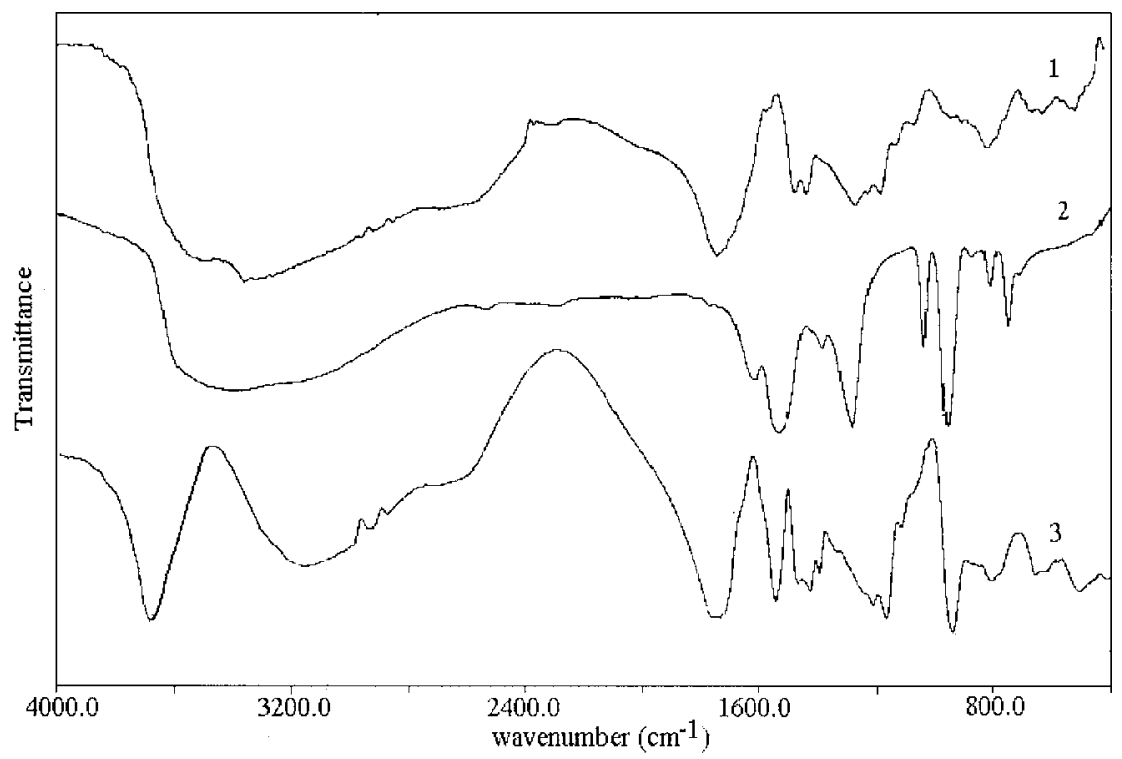

Figure 2. FTIR spectra of (1) PAA, (2) $\mathrm{UO}_{2}\left(\mathrm{NO}_{3}\right)_{2} \cdot 3 \mathrm{H}_{2} \mathrm{O}$, and (3) $\mathrm{PAA} / \mathrm{UO}_{2}^{2+}$ polycomplex $(n=2)$ in the solid state.

has been observed on potentiometry and conductometry curves. The corresponding changes in the $\mathrm{pH}$ and conductivity of a pure PAA solution is shown for comparison. The variation of the $\mathrm{pH}$ and conductivity values of PAA solutions is typical for the dilution of weak polyelectrolytes.

IR spectra of PAA, $\mathrm{UO}_{2}\left(\mathrm{NO}_{3}\right)_{2} \cdot 3 \mathrm{H}_{2} \mathrm{O}$, and PAA saturated with uranyl ions are presented in Figure 2. The complex spectra show that the carbonyl stretching absorption band of PAA at 1722 $\mathrm{cm}^{-1}$ is shifted to $1730 \mathrm{~cm}^{-1}$ because of the complexation of carboxyl groups with uranyl ions, and a new band appears at $1749 \mathrm{~cm}^{-1}$.

It is clear that complex formation is accompanied by the ionization of carboxylic groups of PAA. When ionization takes place, resonance is possible between $\mathrm{C}-\mathrm{O}$ groups in the $\mathrm{COO}^{-}$groups. In fact, an antisymmetric vibration band of $\mathrm{COO}^{-}$ appears at $1539 \mathrm{~cm}^{-1}$. The spectra of PAA in the $3000-3500-\mathrm{cm}^{-1}$ region exhibit two bands: a band at $3353 \mathrm{~cm}^{-1}$, attributed to hydrogenbonded hydroxyl groups (self-associated), and a broad band at $3500 \mathrm{~cm}^{-1}$, assigned to free hydroxyl groups. ${ }^{23}$ However, upon complex formation, a new narrow band can be observed at higher frequencies $\left(3641 \mathrm{~cm}^{-1}\right)$, indicating the presence of nonassociating $\mathrm{OH}$ groups of PAA resulting from the disturbance of $\mathrm{PAA} / \mathrm{H}_{2} \mathrm{O}$ association by complexation with $\mathrm{UO}_{2}$ ions.

It is known that free uranyl ions in aqueous solutions are coordinated by five molecules of wa- ter $\left[\mathrm{UO}_{2}\left(\mathrm{H}_{2} \mathrm{O}\right)_{5}\right]^{2+} .{ }^{24} \mathrm{~A}$ comparison of the spectrum of pure PAA and the complex shows that there is a broad peak of the stretching vibration of $\mathrm{O}-\mathrm{H}$ groups at $3180 \mathrm{~cm}^{-1}$ for the complex, which indicates the presence of water molecules coordinated to the complex. ${ }^{25}$

A new strong absorption band appearing at 934 $\mathrm{cm}^{-1}$ in the polycomplex spectrum can be attributed to the complexed uranyl ions. Indeed, the characteristic stretching band for the $\mathrm{O}-\mathrm{U}-\mathrm{O}$ structure in uranyl ions has been observed at 948 $\mathrm{cm}^{-1} \cdot 26$

A study of the emission spectra of uranyl-ioncomplexed PAA can yield important information regarding the metal-ion-binding mechanism of this polymer. All electrons in the strongly bound $\mathrm{O}-\mathrm{U}-\mathrm{O}$ structure are paired. This means that the ground electronic level is a singlet. To form higher energy electronic states, one of the binding electrons is transferred to a nonbonding $5 \mathrm{f}$ molecular orbital of the uranyl ion. Thus, the emission spectrum is the result of the transitions from the first excited electronic level to the ground singlet and the vibrational levels associated with the singlet. ${ }^{27}$ The emission intensity of uranyl ions is characterized by a shorter lifetime because coordinated water molecules serve as efficient quenchers of the luminescence. ${ }^{28}$ The emission spectra of $\mathrm{UO}_{2}^{2+}$ aqueous solutions in the absence and presence of PAA with different concentrations under excitation at $310 \mathrm{~nm}$ are shown in 

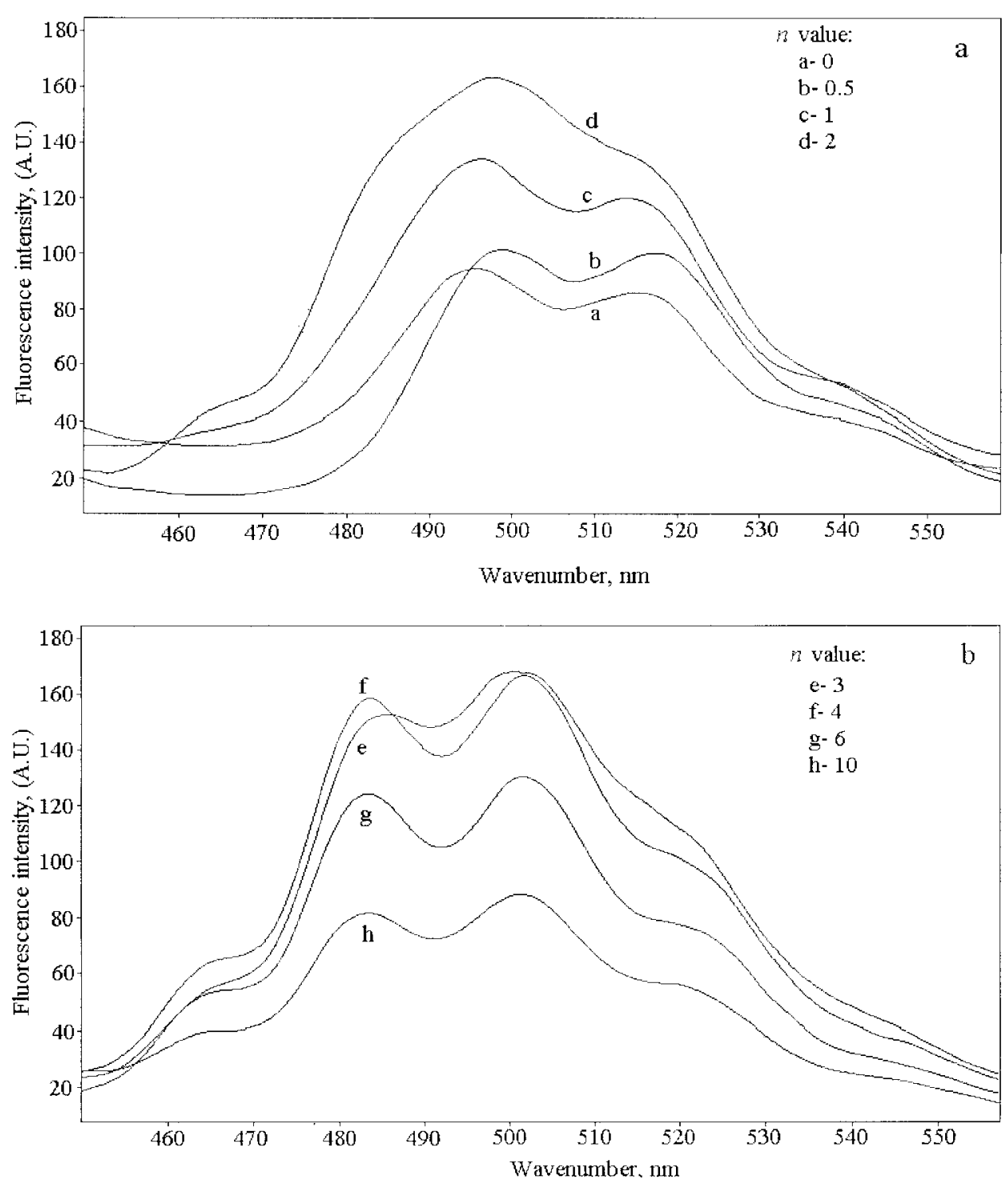

Figure 3. Emission spectra of aqueous $\mathrm{UO}_{2}^{2+}$ at different values of $n=$ PAA on a repeating unit basis/ $\mathrm{UO}_{2}^{2+}$ : (a) $n \leq 2$ and (b) $n>3\left(\lambda_{\text {ex }}=310 \mathrm{~nm}\right)$.

Figure 3. The peaks observed for $\mathrm{UO}_{2}^{2+}$ aqueous solutions without PAA, located at 499 and $517 \mathrm{~nm}$, and the shoulder at $540 \mathrm{~nm}$ are in good agreement with the results of Moulin et al. ${ }^{21}$ When $n$ is less than 2, an increase in the emission intensity is strongly related to the PAA concentration, and the emission peaks shift to lower wavelengths [Fig. $3(\mathrm{a})]$ because of the coordination of $\mathrm{UO}_{2}^{2+}$ ions by PAA ligands. This can be explained by the expulsion of some of the water molecules coordinated to uranyl ions by complex formation. ${ }^{16}$ The increase in the PAA concentration is accompanied by significant changes in the spectral shape with the appearance of a new shoulder at $483 \mathrm{~nm}$ [Fig. 3(b)] until the stoichiometric ratio reaches the value of $n=2$ (PAA on a repeating unit basis $/ \mathrm{UO}_{2}^{2+}=2: 1 \mathrm{~mol} /$ $\mathrm{mol})$. The formation of shoulders around the main peaks of $\mathrm{UO}_{2}^{2+}$ has also been observed for the complexation of uranyl ions with some $\alpha$-substituted carboxylic acids in the work of Moll et al. ${ }^{29}$ For higher $n$ values (PAA on a repeating unit basis/ $\mathrm{UO}_{2}^{2+}>4$ ), however, a decrease in the emission intensity has been observed, which can be explained by the quenching effect of PAA in an excess of $\mathrm{UO}_{2}^{2+}$ complex stoichiometry with nondissociated groups of the polyelectrolyte. Further studies on the complexation of PAA with uranyl ions by luminescence spectroscopy are in progress. 

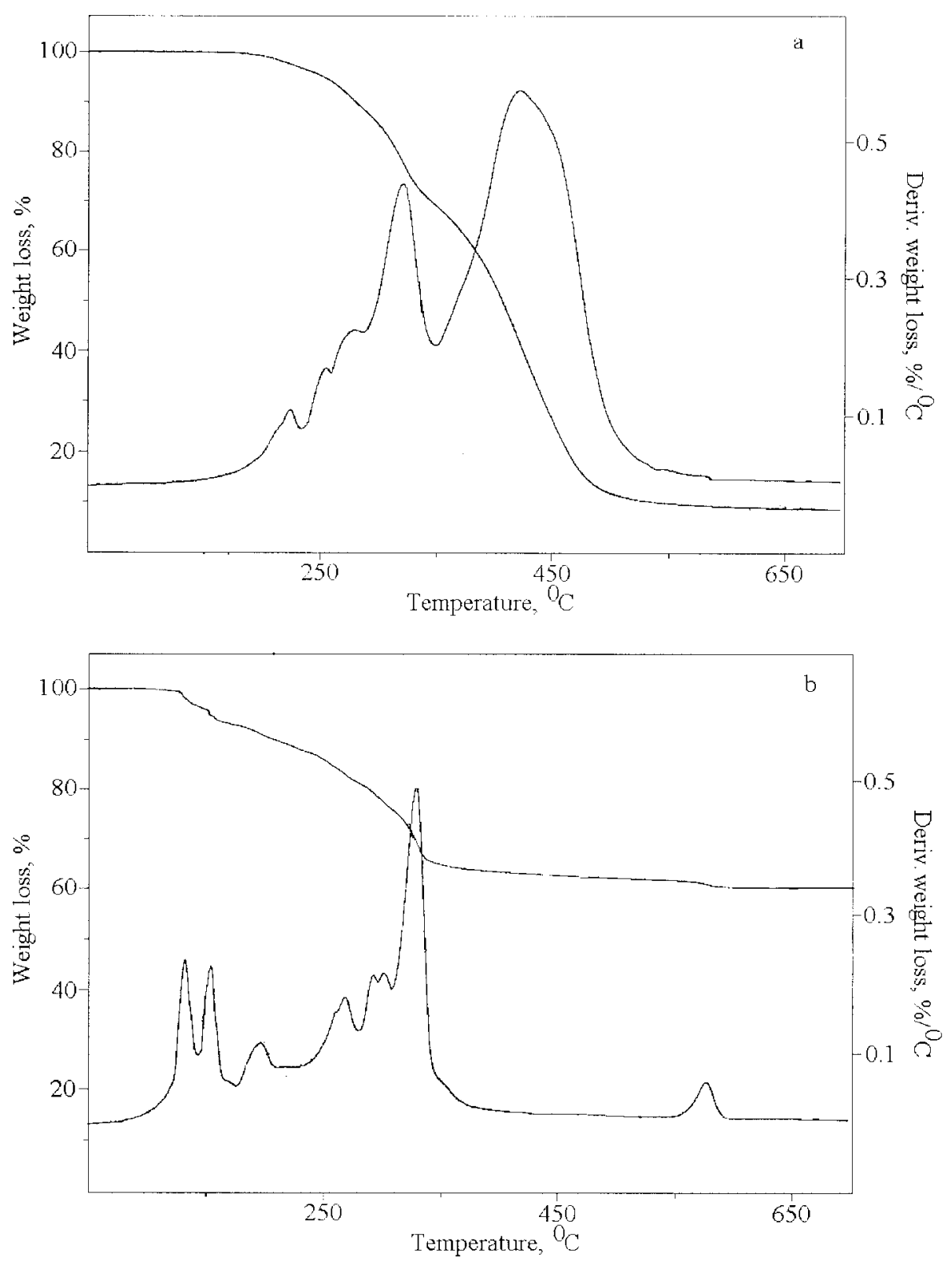

Figure 4. TGA thermograms of (a) solid PAA, (b) solid uranyl nitrate trihydrate, and (c) solid PAA/ $\mathrm{UO}_{2}^{2+}$ complex $(n=2)$.

The thermal behavior of the polycomplex in the solid state was investigated with TGA and DSC methods. Figure 4 presents TGA results for pure PAA, uranyl nitrate trihydrate, and their complex.

It is known that PAA has poor thermal stability and is characterized by a two-stage degradation process [Fig. 4(a)]. The first stage starts at $180^{\circ} \mathrm{C}$ and is due to intermolecular and intramolecular anhydride formation with the consequent decarboxylation process of free carboxylic and an- hydride groups ( $31 \mathrm{wt} \%$ loss). The second stage starts at $370{ }^{\circ} \mathrm{C}$ with a weight loss of $61 \%$ and is accompanied by the degradation and decomposition of the polymer with eventual carbonization. These data are in good agreement with the literature. ${ }^{30}$

The weight-loss curve of $\mathrm{UO}_{2}\left(\mathrm{NO}_{3}\right)_{2} \cdot 3 \mathrm{H}_{2} \mathrm{O}$ is characterized by several stages of decomposition. The first stage is between 80 and $205{ }^{\circ} \mathrm{C}$ [Fig. 4(b)] and is related to a gradual loss of water molecules. The effective weight loss (25\%) occurs 


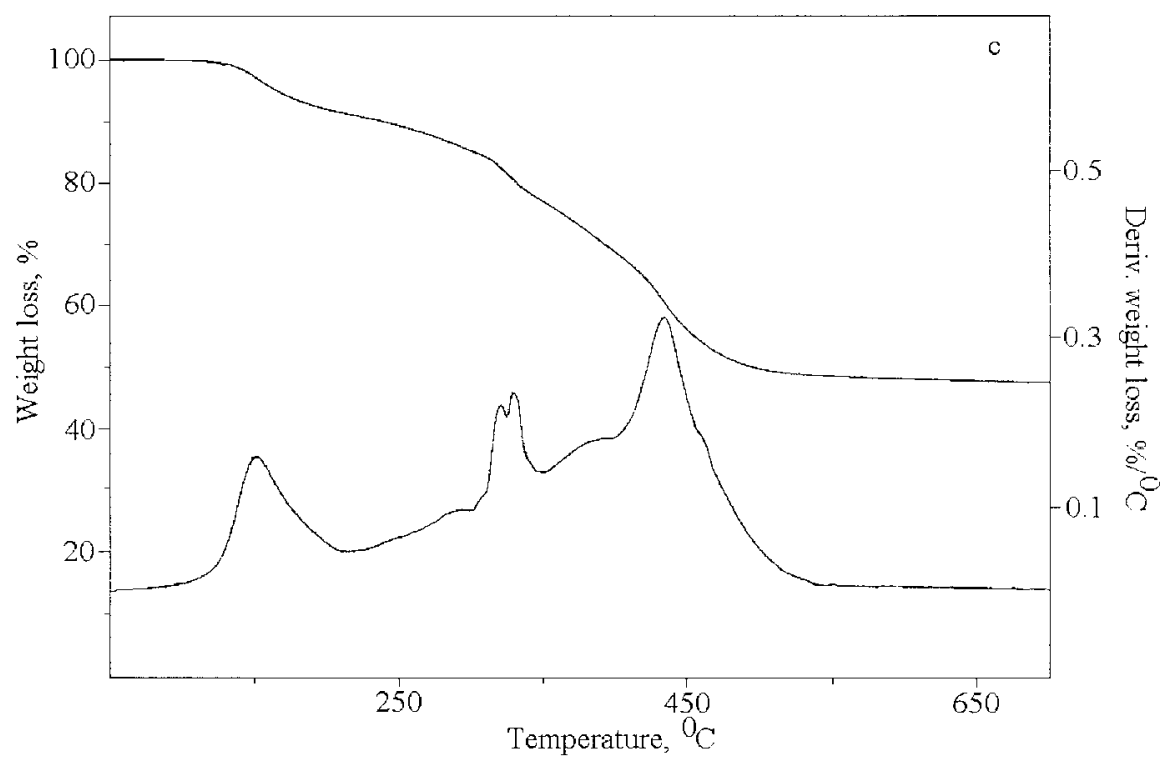

Figure 4. (Continued)

at $240-350{ }^{\circ} \mathrm{C}$ and can be explained by $\mathrm{NO}_{2}$ molecules being released and $\mathrm{UO}_{3}$ being the final product. ${ }^{31}$

The thermal decomposition of polymer-metal complexes depends on the nature of the polymer backbone and the type of metal ion. ${ }^{8,12}$ Three stages of decomposition have been observed for the PAA/ $/ \mathrm{UO}_{2}^{2+}$ complex. The first stage occurs at
$120{ }^{\circ} \mathrm{C}$ with a weight loss of $9 \%$ and is likely due to the elimination of water molecules bound to $\mathrm{UO}_{2}^{2+}$ and water molecules released from anhydride formation by unbound carboxyl groups of PAA. The second stage starts at $293{ }^{\circ} \mathrm{C}$ and is attributed to the decarboxylation process of carboxylate groups of PAA and $\mathrm{UO}_{3}$ formation $(11 \%$ weight loss). The third degradation stage is sim-

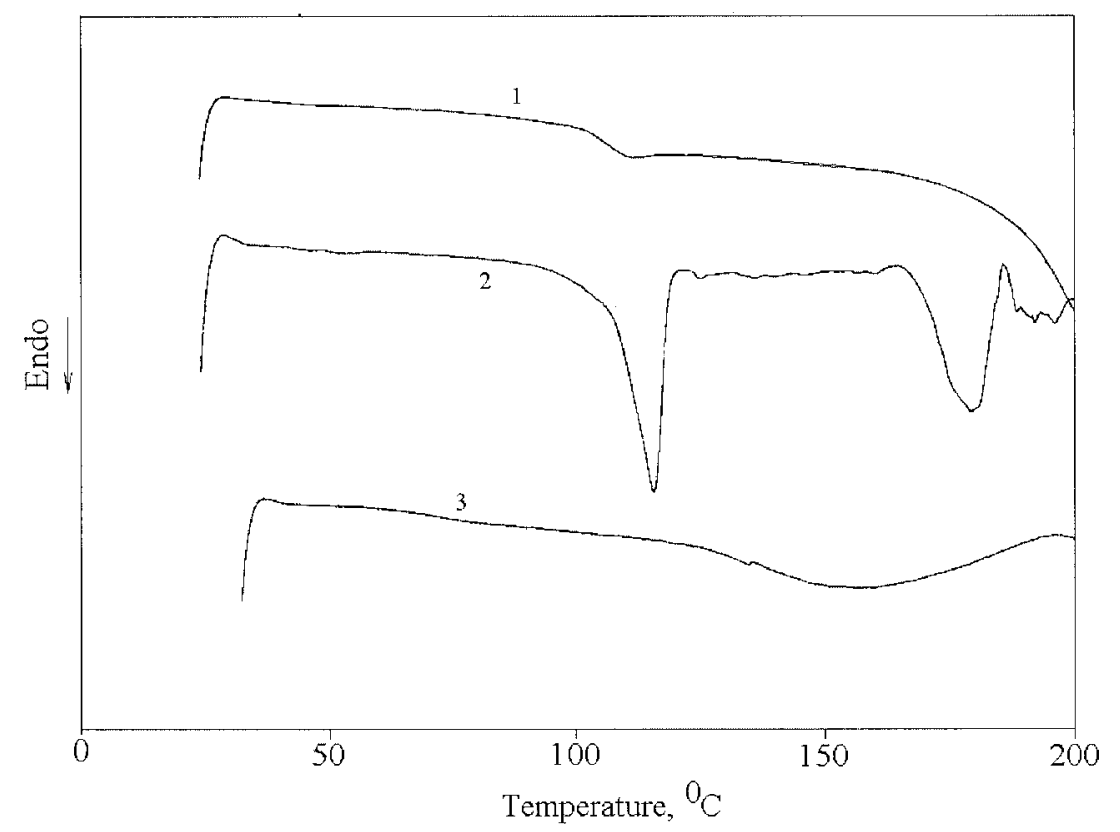

Figure 5. DSC thermograms of (1) PAA, (2) uranyl nitrate trihydrate, and (3) PAA/ $\mathrm{UO}_{2}^{2+}$ complex $(n=2)$ in the solid state. 
ilar to pure PAA and is connected to the yielding of complex degradation products. The residual weight is about $48 \%$ and is due to the presence of a $\mathrm{UO}_{3}$ product with high thermal stability. It is important to note that the theoretical calculation of the polycomplex water loss $(8.72 \%)$ is in agreement with the experimental data $(\sim 9 \%)$ and corresponds to the loss of two water molecules that are coordinated by $\mathrm{UO}_{2}^{2+}$. As the TGA results show, the polycomplex decomposition includes the main stages of PAA and uranyl nitrate trihydrate degradation.

Pure PAA, uranyl nitrate trihydrate, and its complex were studied by DSC as well (Fig. 5).
PAA shows a distinct glass transition at $106{ }^{\circ} \mathrm{C} .{ }^{32}$ $T_{\mathrm{g}}$ for the $\mathrm{PAA} / \mathrm{UO}_{2}^{2+}$ polycomplex could not be observed up to $120^{\circ} \mathrm{C}$, the onset of the first stage of thermal degradation. $T_{\mathrm{g}}$ of the polycomplex is, therefore, supposed to be higher than the degradation temperature of the complex, and this is indicative of a strong interaction between the uranyl ions and PAA.

According to the results obtained so far, the following mechanism of complex formation is possible:

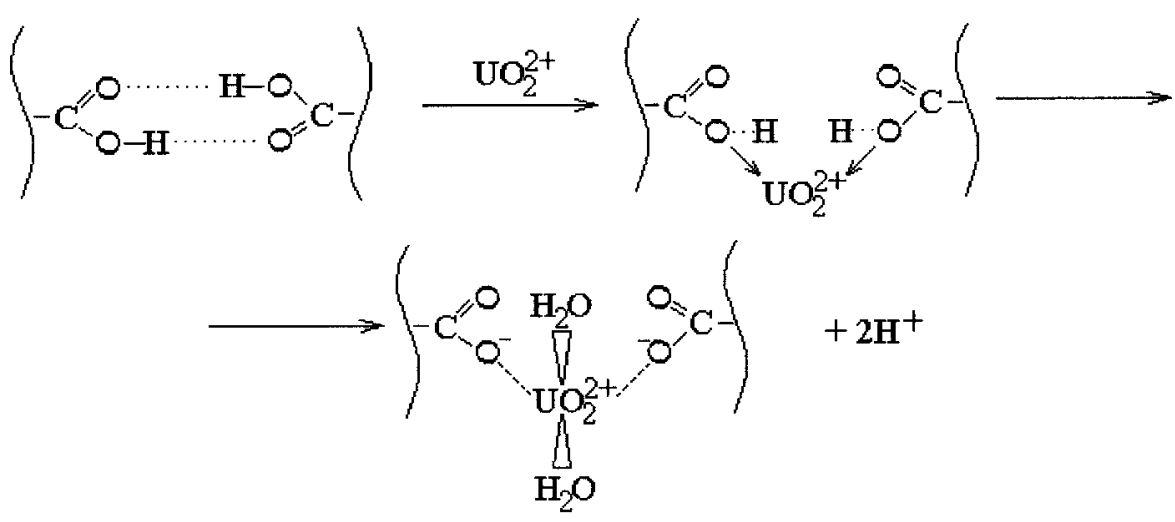

It has been found in the literature ${ }^{33}$ that a low molecular analogue of repeating units of PAA, propionic acid, forms two types of complexes with $\mathrm{UO}_{2}^{2+}: \mathrm{UO}_{2}\left(\mathrm{C}_{2} \mathrm{H}_{5} \mathrm{COO}\right)_{2}$ in the absence of water and $\mathrm{UO}_{2}\left(\mathrm{C}_{2} \mathrm{H}_{5} \mathrm{COO}\right)_{2} \cdot 2 \mathrm{H}_{2} \mathrm{O}$ in the presence of water. This is in good agreement with our proposed structure. Our findings show that in the $\mathrm{PAA} / \mathrm{UO}_{2}^{2+}$ complex structure, the coordination number of uranyl ions is reduced to four, most likely because of steric hindrance induced by the polymer chain segments to which the complexing carboxylate groups of PAA are attached.

\section{CONCLUSIONS}

We have attempted to understand the mechanism of interaction between PAA and uranyl ions in aqueous solutions and confirmed the restrictive role of Coulombic interactions. It has been shown that approximately $1 \mathrm{~mol}$ of uranyl ions is coordinated by $2 \mathrm{~mol}$ of carboxylic groups of PAA. This result is related to the conductivity, potentiometry, and luminescence spectroscopy studies.
FTIR and thermal characterization studies performed on complexes in the solid state have allowed us to verify the strong electrostatic interaction between the uranyl ions and the pendant groups of PAA.

A. V. Dubolazov and G. S. Azhgozhinova are grateful to the International Atomic Energy Agency for the fellowship provided within the framework of TC Project KAZ/ 8/002. They also extend their appreciation to V. V. Khutoryanskiy for his support and encouragement.

\section{REFERENCES AND NOTES}

1. Rivas, B. L.; Pereira, E. D.; Moreno-Villoslada, I. Prog Polym Sci 2003, 28, 173-208.

2. Güven, O.; Şen, M.; Karadağ, E.; Saraydin, D. Rad Phys Chem 1999, 56, 381-386.

3. Bodzek, M.; Korus, I.; Loska, K. Desalination 1999, 121, 117-121.

4. Pekel, N.; Savaş, H.; Güven, O. Colloid Polym Sci 2002, 280, 46-51.

5. Tsuchida, E.; Nichide, H. Adv Polym Sci 1977, 24, $1-17$. 
6. Molyneux, P. Water-Soluble Synthetic Polymers: Properties and Behavior; CRC: Boca Raton, FL, 1982; Vol. 2.

7. Kuila, D.; Blay, G. A.; Borjas, R. E.; Hughes, S.; Maddox, P.; Rice, K.; Stansbury, W.; Laurel, N. J Appl Polym Sci 1999, 73, 1097-1115.

8. Sebastian, N.; George, B.; Mathew, B. Polym Degrad Stab 1998, 60, 371-375.

9. Roma-Luciow, R.; Saraff, L.; Morcellet, M. Polym Bull 2000, 45, 411-418.

10. Bakırcıoğlu, Y.; Şeren, G.; Akman, S. Spectrochim Acta Part B 2000, 55, 1129-1133.

11. Pochard, I.; Foissy, A.; Couchot, P. Colloid Polym Sci 1999, 277, 818-826.

12. Cardenas, G.; Munoz, C.; Carbacho, H. Eur Polym J 2000, 36, 1091-1099.

13. Rosendo, A.; Flores, M.; Cordoba, G.; Rodriguez, R.; Arroyo, R. Mater Lett 2003, 57, 2885-2893.

14. Lujan-Upton, H.; Okamoto, Y.; Walser, A. J Appl Polym Sci 1997, 35, 393-398.

15. Meinrath, G.; Lis, S.; Stryla, Z.; Noubactep, C. J Alloys Compd 2000, 300, 107-112.

16. Nagata, I.; Okamoto, Y. Macromolecules 1983, 16, 749-753.

17. Nishide, H.; Oki, N.; Tsuchida, E. Eur Polym J 1982, 18, 799-802

18. Leroy, D.; Martinot, L.; Jerome, C.; Jerome, R. Polymer 2001, 42, 4589-4596.

19. Morlay, C.; Cromer, M.; Mouginot, Y.; Vottori, O. Talanta 1998, 45, 1177-1188.

20. Morlay, C.; Cromer, M.; Mouginot, Y.; Vottori, O. Talanta 1999, 48, 1159-1166.
21. Moulin, C.; Decambox, P.; Moulin, V.; Decaillon, J. G. Anal Chem 1995, 67, 348-353.

22. Pekel, N.; Güven, O. Colloid Polym Sci 1999, 277, 570-573.

23. Luo, X.; Goh, S. H.; Lee, S. Y. Macromol Chem Phys 1999, 200, 399-404.

24. Sarakha, M.; Botle, M.; Burrows, H. D. J Photochem Photobiol Part A 1997, 107, 101-106.

25. Weast, R. C. Handbook of Chemistry and Physics, 53rd ed.; CRC Press: Cleveland, 1973; pp F197F205.

26. Pekel, N.; Şahiner, N.; Akkaş, P.; Güven, O. Polym Bull 2000, 44, 593-600.

27. Leung, A. F.; Hayashibara, L.; Spadaro, J. J Phys Chem Solids 1999, 60, 299-304.

28. Meiranth, G. Aquatic Chemistry of Uranium; Freiberg On-Line Geoscience: 1998; Vol. 1, pp 22-23, http: \\www.geo.tu_freiberg $\backslash$ fog (June 19, 2003).

29. Moll, H.; Geipel, G.; Reich, T.; Bernhard, G.; Fanghanel, T.; Grenthe, I. Radiochim Acta 2003, 91, 11-20.

30. Garay, T. M.; Llamas, C. M.; Iglesias, E. Polymer 1997, 38, 5091-5096.

31. Duval, C. Inorganic Thermogravimetric Analysis, 2nd ed.; Elsevier: 1963; pp 666-667.

32. Brandrup, J.; Immergut, E. H. Polymer Handbook, 3rd ed.; Wiley-Interscience: New York, 1989; Chapter $6, \mathrm{p} 215$.

33. Chernyaev, I. I. Complex Compounds of Uranium; Israel Program for Scientific Translations, Ltd.: Jerusalem, 1966; p 319. 